\title{
Farklı Organik Gübrelerin Mısır-Buğday Ekim Nöbetinde Buğdayın Verimine Bakiye Etkileri
}

\author{
Ilknur GÜMÜȘ ${ }^{* *} \quad$ Cevder ȘEKER
}

'Selçuk Üniversitesi Ziraat Fakültesi Toprak Bilimi ve Bitki Besleme Bölümü, KONYA

*Sorumlu yazar e-posta (Corresponding author e-mail): ersoy@selcuk.edu.tr
Geliș tarihi (Received) : 20.04 .2013
Kabul tarihi (Accepted) : 28.01 .2014

Öz

Bu araștırma, arazi șartlarında, tesadüf blokları deneme deseninde, dört tekerrürlü olarak iki farklı lokasyonda yürütülmüștür. Taze tavuk gübresi (TTG), olgun tavuk gübresi (OTG) ve zeolitin (Z) buğday verimine bakiye etkileri araștırılmıștır. Araștırmadaki deneme konuları; kontrol, Z (150 kg da'1), TTG (1000 kg da-1), OTG (1000 kg da-1), TTG+Z (1000 kg da $\left.{ }^{-1}+150 \mathrm{~kg} \mathrm{da-1)} \mathrm{ve} \mathrm{OTG+Z} \mathrm{(1000} \mathrm{kg} \mathrm{da}+150 \mathrm{~kg} \mathrm{da}^{-1}\right)$ șeklinde olmuștur. Gübre uygulanan parsellerde ilk yıl mısır yetiștirilmiș, mısır hasadından hemen sonra aynı parsellere buğday ekilmiștir. Her iki yılda da uygulamaların buğday verimini istatistiksel olarak önemli Ölçüde etkilediği saptanmıștır. İlk yıl en yüksek buğday verimi (108,44 kg da') OTG+Z uygulamasında, ikinci yıl $\left(240,36 \mathrm{~kg} \mathrm{da}^{-1}\right)$ TTG uygulamasında elde edilmiștir.

Anahtar Kelimeler: Buğday, buğday verimi, organik gübre, zeolit

\section{Residual Effect of Different Organic Manure Application on Wheat Yield in Corn-Wheat Rotation}

\begin{abstract}
This investigation was carried out under field conditions and designed as randomised complete blocks with for replications and two locations. On wheat yield, residual effects of fresh poultry manure (FPM), composted poultry manure (CPM) and zeolite (Z) were investigated. The treatments were Z (150 $\mathrm{kg} \mathrm{da-1}), F P M\left(1000 \mathrm{~kg} \mathrm{da}^{-1}\right), C P M\left(1000 \mathrm{~kg} \mathrm{da}^{-1}\right), F P M+Z\left(1000 \mathrm{~kg} \mathrm{da}^{-1}+150 \mathrm{~kg} \mathrm{da}^{-1}\right), C P M+Z(1000 \mathrm{~kg}$ $\left.\mathrm{da}^{-1}+150 \mathrm{~kg} \mathrm{da} \mathrm{a}^{-1}\right)$. At the first year of experiment, corn was grown in all of the plots. Wheat plant was grown at the same plots after corn harvesting. In both years, applications affected significantly wheat yield. At the first and second years, the highest wheat yield occurred at the application of CPM+Z and FPM as $108,44 \mathrm{~kg} \mathrm{da}^{-1}$ and $240,36 \mathrm{~kg} \mathrm{da}^{-1}$, respectively.
\end{abstract}

Key Words: Wheat, wheat yield, organic manure, zeolite

\section{Gíriș}

Bilim ve tekniğin hızla ilerlediği günümüzde, ülkeler en son gelișmelerden yararlanarak birim alandan daha fazla verim alma çabası içindedirler. Yeryüzünde tarım alanları sınırlı olduğuna göre her gün biraz daha artan dünya nüfusunun beslenmesi için sınırlı olan tarım alanlarından en yüksek verimin alınması zorunlu duruma

gelmektedir. Bunun sonucu olarak, yoğun șekilde kimyasal kaynaklı tarımsal girdiler kullanılmakta buna bağı olarak çevre ve toprak kirliliği ile karșı karșıya kalınmaktadır.

Dünyada uzun yıllardır toprakların fiziksel ve kimyasal özelliklerini iyileștirmek ve verimliliği 
artırmak amacıyla mineral ve organik gübreler ile değișik biyolojik atık maddeleri kullanılmaktadır. Türkiye toprakları organik madde bakımında sınırlı alanlar hariç genellikle fakirdir (Dinç ve ark., 2001). Türkiye'de birçok bölgede, özellikle Orta Anadolu Bölgesinde toprakların organik madde içerikleri $\% 2$ 'nin hatta \%1'in altına düșmüștür (Șeker ve Karakaplan, 1999; Gezgin ve ark., 2002). Orta Anadolu Bölgesinde uygulanan tarım teknikleri, topraklarda organik madde birikimini azaltarak, toprakların verimliliklerinin kaybolmasına neden olmaktadır. Hasat artıklarının (anızın) yakılması ve organik gübrelemenin yetersiz olması toprak verimliliğindeki düșüșün en önemli nedenleridir. Topraklardaki organik madde azlığı, agregatlașma ve agregatların dayanıkııı̆ını önemli ölçüde etkilemektedir (Șeker ve Karakaplan, 1999).

Düșük organik madde içeriği alkali reaksiyonlu ve kireçli Orta Anadolu topraklarında bitki besin elementlerinin yarayıșlıIı̆ını düșürmektedir. Bu da yetiștirilen ürünlerin verim ve kalitesini olumsuz etkilemektedir.

Organik madde eksikliğini gidermek için her türlü bitkisel artıklar, çiftlik gübresi, tavuk gübresi, kompost ve organik yapıdaki sanayi atıkları kullanılabilmektedir. Bu materyaller toprakların fiziksel, kimyasal ve biyolojik özelliklerini iyileștirerek, topraklara besin elementi sağlamakta, dolayısıyla bitkisel üretimde verim ve kaliteyi olumlu etkilemektedirler (Entry ve ark., 1997; Pascual ve ark., 1997; Madejon ve ark., 2001; Kütük ve ark., 2003; Bhattacharya ve ark., 2003; Șeker ve Turhan, 2004).

Organik gübrelerin etkinlikleri mineral gübrelerden farklı olarak daha uzun süre devam etmekte, toprak ve ürün verimi üzerine bakiye etkisi bulunmaktadır. Tavukçuluk, Türkiye'de özellikle her yönüyle son yıllarda çok hızlı bir gelișme göstermiș üretim açısından resmi plan hedeflerini așmıș ve bazı ișletmelerde teknolojinin oldukça ileri düzeyde uygulandığı tarımın bașarıı dallarından birisi haline gelmiștir. Tavuk yetiștiriciliğinin dünyadaki ve ülkemizdeki durumu yıllara göre artıș göstermektedir. Tavuk sayısındaki artıșa paralel olarak gübre materyali olan dıșkı miktarında da bir artıș ortaya çıkmaktadır. Ülkemizde, son yirmi yılda tavuk ve tavuk çiftliklerinin sayısı artmıștır. Tavukçuluk sektörünün büyümesi ile birlikte çevreye olan olumsuz etkileri de giderek artmıștır. Tavuk dıșkılarının gübre olarak yanlıș kullanımı; çevresel olarak bazı problemlere yol açmıștır. Çevre üzerindeki estetik etkileri, su kaynaklarına kirlilik etkisi ve çevreye yaymıș olduğu koku gibi olumsuz etkileri bulunmasına rağmen, uygun olarak kullanıldığında toprakların biyolojik aktivitesi ile fiziksel ve kimyasal özelliklerini iyileștirici etkiye sahiptir (Schimitt ve Rehm, 2005). Ayrıca içerdiği besin elementleri ile bitki gelișimini teșvik etmekte ve organik bir materyal olmasından dolayı toprağın su ve besin maddesi tutma kapasitesini artırmaktadır (Sloan ve ark., 2005). Zeolit; alkali toprak katyonları içeren, kristal yapıda, kolay ve bol bulunan, üç boyutlu bir alüminyum silikatdir (Noori ve ark., 2006). Temel özellikleri; yüksek katyon değișim kapasitesine sahip olması, dengeli su alıp verebilmesi ayrıca iyon değișimi, besin alıp verebilme ve asidite ile hava gözenekliliğini düzenleyebilmesi olarak sıralanabilir. Zeolit; $\mathrm{N}$ ve K temin eden, yavaș-verici olarak değerlendirilir. Ayrıca, fazla miktarı toksik etki yapabilecek $\mathrm{NH}_{4}{ }^{\prime} \mathrm{u}$ kanallarına alarak topraktan uzaklaștırır ve amonyak gazı șeklindeki azot kayıplarını azaltmaktadır. Ayrıca istenilen irilikte oldukça kolay sınıflandırılmakta ve yetiștirme ortamlarına elverișli fiziksel özellikler kazandırması dolayısıyla tarımda kullanıımaktadır.

Bu çalıșmanın amacl; Türkiye'de geniș bir ekim alanına sahip buğday bitkisinin verimine TTG, OTG ve bunların zeolitli karıșımlarının bakiye etkilerini mısır-buğday rotasyonunda belirlemektir.

\section{MATERYAL ve YÖNTEM}

Deneme Türkiye șeker Fabrikaları A.Ș Konya - Alakova deneme istasyonu arazisinde gerçekleștirilmiștir $\left(41^{\circ} 82^{\prime} 27^{\prime \prime} .2 \mathrm{~N}\right.$ ve $45^{\circ} 60^{\prime} 15^{\prime \prime} \mathrm{E}$; deniz seviyesinden yükseklik 1015 m). Bölge iklimi kurak - yarı kurak karakterde olup, yıllık ortalama sıcaklık $11,4^{\circ} \mathrm{C}$, yıllık toplam buharlașma $1033 \mathrm{~mm}$ ve yıllık ortalama yağıș 300 mm civarındadır. Bölgedeki kurak periyot Haziran - Eylül döneminde olup, bu alanın yaygın toprak tipi Typic Haploxerepts olup (Soil Survey Staff, 1998), alüviyal materyal üzerinde gelișmiștir (Çizelge 1). Deneme parseli topraklarının pH'sı hafif alkalin ve kireç içeriği yüksek, tuz ve organik madde içeriği düșük olup, tekstürleri CL'dir. Her iki deneme parselinin N, P, Fe ve $\mathrm{Cu}$ içerikleri yeterli; $\mathrm{K}$ içeriği fazla; $\mathrm{Mn}$ ve $\mathrm{Zn}$ içerikleri ise az düzeydedir (FAO, 1990). Denemede kullanılan TTG ve OTG'nin özellikleri Çizelge 2'de verilmiștir. Buna göre TTG'nin pH'sı 8,42 iken, OTG'nin 8,28 olarak ölçülmüștür. Gübrelerin EC değerleri ise TTG ve OTG sırasıyla; 10,41 dS m-1 ve $6,21 \mathrm{dS} \mathrm{m}^{-1}$ olarak ölçülmüștür. Gübrelerin toplam azot içerikleri TTG'de \%1,93 iken, OTG'de \%2, 99 bulunmuștur. Gübrelerin organik karbon içerikleri TTG ve OTG; \%29, 99 ve \%32, 90 ölçülmüștür. 
Çizelge 1. Deneme yeri toprağının bazı fiziksel ve kimyasal özellikleri

Table 1. Some physical and chemical properties of the soil experiment area

\begin{tabular}{|c|c|c|c|}
\hline Deneme yeri & I & II & Referans kaynaklar \\
\hline Deneme yılı & 2008 & 2009 & \\
\hline Kil (\%) & 45,8 & 43 & (Day, 1965) \\
\hline Silt (\%) & 30 & 30 & \\
\hline Kum (\%) & 24,2 & 27 & \\
\hline Tekstür sınıfı & $\mathrm{CL}$ & $C L$ & \\
\hline $\mathrm{pH}\left(\mathrm{H}_{2} \mathrm{O} ; 1: 2.5\right)$ & 8,26 & 8,25 & (Tüzüner, 1 ९९०) \\
\hline EC $\left(\mathrm{H}_{2} \mathrm{O} ; 1: 2.5\right) \mu \mathrm{S} \mathrm{m}^{-1}$ & 177,1 & 232,7 & (Tüzüner, 1990) \\
\hline Organik madde (\%) & 2,10 & 1,60 & (Bayraklı, 1987) \\
\hline $\mathrm{CaCO}_{3}(\%)$ & 20,62 & 15,22 & (Hızalan ve Ünal, 1966) \\
\hline Tarla kapasitesi (\%) & 29,4 & 29,84 & (Demiralay, 1993) \\
\hline Solma noktası (\%) & 15,63 & 18,43 & (Demiralay, 1993) \\
\hline KDK (cmol kg-1) & 28,41 & 27,19 & (U.S S. Lab. Staff, 1954) \\
\hline Toplam azot (\%) & 0,096 & 0,093 & (Bremner, 1982) \\
\hline$P\left(\mathrm{mg} \mathrm{kg}^{-1}\right)$ & 16,48 & 24,54 & (Lindsay ve Norvel, 1978) \\
\hline$K\left(\mathrm{mg} \mathrm{kg}^{-1}\right)$ & 492,86 & 548,85 & (Lindsay ve Norvel, 1978) \\
\hline $\mathrm{Cu}\left(\mathbf{m g ~ k g}{ }^{-1}\right)$ & 1,30 & 1,20 & (Lindsay ve Norvel, 1978) \\
\hline $\mathrm{Fe}\left(\mathrm{mg} \mathrm{kg}^{-1}\right)$ & 5,35 & 7,84 & (Lindsay ve Norvel, 1978) \\
\hline $\mathrm{Mn}\left(\mathrm{mg} \mathrm{kg} \mathbf{g}^{-1}\right)$ & 9,45 & 11,56 & (Lindsay ve Norvel, 1978) \\
\hline $\mathrm{Zn}\left(\mathrm{mg} \mathrm{kg}{ }^{-1}\right)$ & 0,32 & 0,34 & (Lindsay ve Norvel, 1978) \\
\hline
\end{tabular}

KDK: Katyon değișim kapasitesi

Çizelge 2. Denemede kullanılan TTG ve OTG'nin bazı Özellikleri

Table 2. Properties of the fresh and composted poultry manure

\begin{tabular}{|c|c|c|c|}
\hline Özellik & TTG & OTG & $\begin{array}{l}\text { Referans } \\
\text { kaynaklar }\end{array}$ \\
\hline $\mathrm{pH}\left(\mathrm{H}_{2} \mathrm{O}, 1: 2.5\right)$ & 8.42 & 8.28 & (Jackson, 1962) \\
\hline $\mathrm{EC}\left(\mathrm{H}_{2} \mathrm{O}, 1: 2.5\right) \mathrm{d} \mathrm{S} \mathrm{m}^{-1}$ & 10.41 & 6.29 & (Jackson, 1962) \\
\hline Organik karbon (\%) & 29,99 & 32,90 & (Yanma kaybı) \\
\hline $\mathbf{N}(\%)$ & 1,93 & 2,99 & (Bayrakli, 1987) \\
\hline $\mathrm{C} / \mathrm{N}$ & 15,54 & 11,00 & \\
\hline
\end{tabular}

\section{Deneme Deseni}

Calıșma tesadüf parselleri deneme deseninde dört tekerrür ve 6 faktörlü olarak planlanmıș ve iki yıl sürdürülmüștür. Deneme parseli ebatları 2,8 m

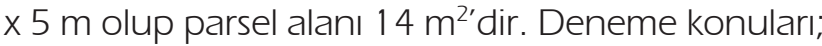
kontrol (hiçbir gübre uygulaması yapılmamıștır),

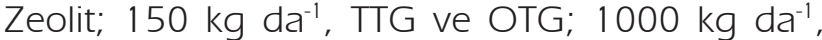
$\Pi \mathrm{TG}+Z$ ve OTG+Z; $1000 \mathrm{~kg} \mathrm{da-1}+150 \mathrm{~kg} \mathrm{da}^{-1}$ șeklinde hazırlanmıștır. TTG, OTG ve Zeolit homojen bir șekilde her bir parsele tırmıkla $10 \mathrm{~cm}$ derinliğe karıștırılmıștır. Uygulamalardan sonra her bir parselde çizelle açılan tohum yataklarına Pionner 3394 mısır tohumu ekilmiștir. Mısır hasadından sonra, aynı parsellere $18 \mathrm{~cm}$ sıra arası ve dekara 20 kg ekmeklik Tosunbey buğday çeșidi ekilmiștir.
Buğday bitkisine herhangi bir gübre uygulaması yapılmamıș, sadece yağıș yetersizliğinde sulanmıștır. Ayrıca, yabancı ot mücadelesi herbisitler kullanılarak yapılmıștır. Olgunlașan buğdaylar 1 m genișliğinde ve $1 \mathrm{~m}$ uzunluğunda toplam $1 \mathrm{~m}^{2}$ hasat alanı olacak șekilde el ile hasat edilmiș ve verim $\mathrm{kg} \mathrm{da}^{-1}$ olarak hesaplanmıștır.

\section{İstatistiksel Değerlendirmeler}

Buğday verim değerleri varyans analizine tabi tutulmuș, önemli çıkan değerler arasındaki farklıı̆ belirlemek için LSD testi uygulanmıștır (Minitab, 1995). 


\section{SONUÇLAR VE TARTIȘMA}

Arazi șartlarında yürütülen iki yıllık deneme sonucunda, mısır bitkisi için yapılan farklı organik gübre uygulamalarının, mısır bitkisinden sonra ekilen buğday bitkisinin verimine bakiye etkisinin istatistiksel olarak önemli olduğu belirlenmiștir (Șekil 1).

Birinci yıl (2008), Kontrol uygulaması ile kıyaslandığında, yapılan tüm uygulamalar buğday verimini artırmıștır. En yüksek buğday verimi 108,44 $\mathrm{kg} \mathrm{da}^{-1}$ ile OTG $+Z$ uygulamasında elde edilirken, en düșük buğday verimi $68,65 \mathrm{~kg} \mathrm{da}{ }^{-1}$ ile Kontrol uygulamasında elde edilmiștir (Șekil 1). Zeolit uygulaması mısırdan sonra ekilen buğday verimine bakiye etki yapmıs ve kontrol uygulamasına göre verimde \% 40,72'lik bir artıș yapmıștır. OTG ve OTG $+Z$ uygulamaları ise, verimde sırasıyla \% 44,07 ve \% 57,96'lık bir artıș yapmıșlardır.

İkinci yıl (2009), Kontrol uygulaması ile kıyaslandığında $\Pi T G$, OTG, $\Pi \mathrm{OG}+Z$ ve $\mathrm{OTG}+Z$ uygulamaları buğday verimini artıırken, Zeolit uygulaması Kontrole oranla buğday verimini artırmasına rağmen istatistiksel olarak etkisi önemsiz olmuștur. En yüksek buğday verimi 240,36 kg da-1 ile TTG uygulamasında elde edilirken, en düșük buğday verimi $189,93 \mathrm{~kg} \mathrm{da}{ }^{-1}$ ile Kontrol uygulamasında elde edilmiștir (Șekil 1). TTG ve $T \mathrm{G}+Z$ uygulamaları mısırdan sonra ekilen buğday verimine bakiye etki yapmıș ve kontrol uygulamasına göre verimde sırasılyla, \% 26,63 ve \% 17,55'lik bir artıș yapmıșlardır.

Yıllar ortalaması bakımından ise, tüm uygulamalar Kontrol uygulaması ile kıyaslandığında buğday verimini artırmıștır. En yüksek buğday verimi 169,46 $\mathrm{kg} \mathrm{da}^{-1}$ ile TT uygulamasında elde edilirken, en düșük buğday verimi $129,3 \mathrm{~kg} \mathrm{da} \mathrm{d}^{-1}$ ile Kontrol uygulamasında elde edilmiștir (Șekil 1). Zeolit, TTG ve TTG+Z uygulamaları mısırdan sonra ekilen buğday verimine bakiye etki yapmıș ve kontrol uygulamasına göre verimde sırasıyla, \% 11,96, \% 31,13 ve $\%$ 22,22'lik bir artıș yapmıșlardır.

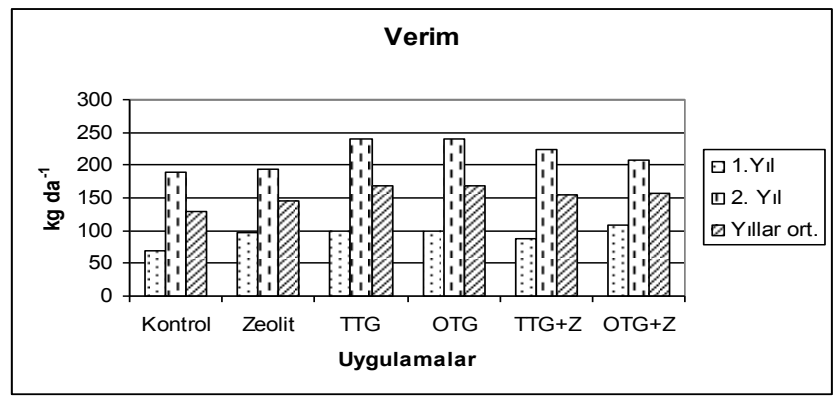

Șekil 1 Uygulamaların Buğday Verimine Bakiye Etkisi (TTG; Taze tavuk gübresi, OTG; Olgun tavuk gübresi, Z; Zeolit)

Figure 1. Residual effect of applications on wheat yield
Yapılan çalıșma sonucunda mısır bitkisine uygulanan farklı organik gübrelerin, mısır hasadından sonra ekilen buğday bitkisinin verimine bakiye etkisinin önemli olduğu, Zeolit, TTG ve OTG uygulamalarının bakiye etkisinin olduğu belirlenmiștir. Her iki yıl ve yıllar ortalamasına göre yapılan tüm uygulamalar buğday veriminde artıșlara neden olmuștur. İlk yıl buğday bitkisinde kök çürüklüğü hastalığının görülmesinden dolayı verimdeki artıș yetersiz seviyede olmuștur. Uygulamalar organik gübre ve zeolitin etkisinin tek yönlü olmadığını bitkinin verimsel özelliklerini de olumlu yönde etkilediğini göstermektedir. Șeker ve Turhan 2006, yaptıkları 3 yıllık çalıșma sonucunda tavuk gübresi uygulamasının buğday verimini artırmadaki bakiye etkisinin yapılan diğer uygulamalardan (çöp gübresi, leonardit, humikfulvik asit) daha fazla olduğunu belirtmișlerdir. Organik gübrelerin bakiye etkileri ile ilgili benzer sonuçlar ceșitli araștırıcilar tarafından da ifade edilmiștir (Chakrabarti ve ark., 2000; Madejon ve ark., 2001; Bhattacharyya ve ark., 2003; Șeker ve Turhan, 2006).

\section{Teșekkür:}

Bu çalıșma Illknur GÜMÜȘ'ün Doktora tezinin bir kısmıdır. Bu çalıșmayı (Proje no: 08101014) destekleyen Selçuk Üniversitesi Bilimsel Araștırma Projeleri Koordinatörlüğü' ne teșekkür ederiz.

\section{KAYNAKLAR}

Bayraklı F (1987). Toprak ve Bitki Analizleri. 19 Mayıs Üniv., Ziraat Fak., Kitap No: 17, Samsun.

Bhattacharyya P, Chakrabarti K, Chakraborty A (2003). Residual Effects of Municipal Solid Waste Compost on Microbial Biomass and Activities in Mustard Growing Soil. Archives of Agronomy and Soil Science 49, 585-592.

Bremner J, Mulvaney C S (1982). Nitrogen-total. In Methods of Soil Analysis. Part 2. Agronomy 9. Physical and Microbiological Properties. Eds. A L Page, R R Miller, DR Keeney. ASA, Madison WI. Pp. 596-622.

Chakrabarti V, Sarkar B, Chakrabarti A, Banik P, Bagchi D K (2000). Organic Recycling for Soil Quality Consevation in Subtropical Plateu Region. J.Agron. Crop Sci., 184, 137-142.

Demiralay i (1993). Toprak Fiziksel Analizleri. A. Ü. Ziraat Fak. Yay. No, 143, Erzurum.

Dinç U, Șenol S, Kapur S, Cangir C, Atalay I (2001). Türkiye Toprakları. C..Ü. Ziraat Fak. Genel Yayın No:51, Adana.

Entry J A, Wood B H, Edwards J H, Wood C W (1997). Influence of Organic by- products and Nitrogen Source on Chemical and Microbiological Status of an Agricultural Soil. Biol. Fertil. Soil, 24: 196-204.

FAO (1990). Statistical database. Available: http://www. fao.org 
Gezgin S, Dursun N, Hamurcu M, Harmankaya M, Önder M, Sade ., Topal A, Soylu S, Akgün N, Yorgancilar M, Ceyhan E, Çiftçi N, Acar B, Gültekin E, Hızalan E., Ünal H (1966). Toprağın Kimyasal Analizleri. A.Ü. Ziraat Fak. Yay. No, 278, Ankara.

Jackson M L (1962). Soil Chemical Analysis. Prentice-Hall, Inc. New York.

Kütük C, Çaycı G, Barab A, Bașkan O, Hartmann R (2003). Effects of Beer Factory Sludge on Soil Properties and Growth of Sugar Beet (Beta vulgaris saccharifera L.) Bioresource Techonology, 90, 75-80.

Lindsay W L, Norvell W A (1978). Development of a DTPA Soil Test For Zn, Fe, Mn and Cu. Soil Amer. J. 42 (3): 421-428.

Madejon E, Lopez R, Murillo J M, Cabera F (2001). Agricultural Use of Three (sugar-beet) Vinasse Composts: Effect on Crops and Chemical Properties of A Cambisol Soil in The Guadauquivir River Valley (SW Spain) Agriculture, Ecosystem and Environment 84, 55-65.

Minitab (1995). Minitab Reference Manuel (Release 7.1) Minitab Inc., State Coll. PA. 16801. USA.

Noori M, Zendehdel M, Ahmadi A (2006). Using Natural Zeolite for İmprovement of Soil Salinity and Crop Yield. Toxicol. Environ. Chem. 88: 77-84.

Pascual J.A, Ayuso M, Hernandez T, Garcia (1997). Phytotoxicity and Fertilizer Value of Different Organic Materials. Agrochemical, 41: 50-62.
Schmitt M, Rehm G (2005). Fertilizing Cropland with Poultry Manure. Available: www.extension.umn.edu/ copyrigt.html.

Sloan D R, Kider G, Jacobs R D (2005). Poultry Manure as

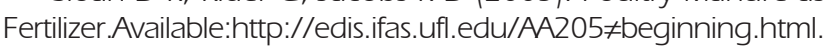

Seker C, Karakaplan S (1999). Konya Ovasında Toprak Özellikleri ile Kırılma Değerleri Arasındaki İlișkiler. Tr. J. of Agriculture and Forestry, 29: 183-190.

Seker C, Turhan M (2004). Effects of Some Organic and Mineral Fertilisers on Yield and Quality of Sugar Beet, International Soil Congress (ISC) Natural Resource Managament for Sustainable Development, 7-10 June Erzurum- Turkey; 43-50.

Șeker C, Turhan M (2006). Bazı Organik ve İnorganik Gübrelerin Șeker Pancarı- Buğday Ekim Nöbetinde Buğdayın Verimine Bakiye Etkileri. S.Ü. Zir. Fak. Der., 19 (20), 43-48.

Tüzüner A (1990). Toprak ve Su Analiz Laboratuarı El Kitabi. Tarım Orman ve Köy İșleri Bakanlığı Köy Hizmetleri Genel Müdürlüğü.

U.S. Salinity Lab.Staff. (1954). Diagnosis and Improvement of Saline and Alkali Soils. U.S. Goverment Handbook No: 60, Printing Office, Washington. 